\title{
Predictability of the California Niño/Niña*
}

\author{
Takeshi Doi, Chaoxia Yuan, Swadhin K. Behera, and Toshio Yamagata \\ Application Laboratory, Japan Agency for Marine-Earth Science and Technology, Yokohama, Japan
}

(Manuscript received 4 February 2015, in final form 30 June 2015)

\begin{abstract}
Predictability of a recently discovered regional coupled climate mode called the California Niño (Niña) off Baja California and California is explored using a seasonal prediction system based on the Scale Interaction Experiment-Frontier, version 1 (SINTEX-F1) coupled ocean-atmosphere general circulation model. Because of the skillful prediction of basin-scale El Niño (La Niña), the California Niño (Niña) that co-occurs with El Niño (La Niña) with a peak in boreal winter is found to be predictable at least a couple of seasons ahead. On the other hand, the regional coupled phenomenon peaking in boreal summer without co-occurrence with El Niño (La Niña) is difficult to predict. The difficulty in predicting such an intrinsic regional climate phenomenon may be due to model deficiency in resolving the regional air-sea-land positive feedback processes. The model may also underestimate coastal Kelvin waves with a small offshore scale, which may play an important role in the generation of the California Niño/Niña. It may be improved by increasing horizontal resolution of the ocean component of the coupled model. The present study may provide a guideline to improve seasonal prediction of regional climate modes for important industrial as well as social applications.
\end{abstract}

\section{Introduction}

Coastal Niño (Niña) phenomena are becoming an interesting topic of climate research after the recent discovery of Ningaloo Niño (Niña) off the west coast of Australia (Feng et al. 2013; Pearce and Feng 2013; Depczynski et al. 2013; Zinke et al. 2014; Kataoka et al. 2014; Tozuka et al. 2014) and California Niño (Niña) off the west coast of California and Baja California (Yuan and Yamagata 2014), in addition to the well-known Benguela Niño/Niña off the west coast of AngolaNamibia (Shannon et al. 1986; Richter et al. 2010). Since the ocean-atmosphere positive feedback mechanism responsible for the coastal warming (cooling) is to some extent similar to the equatorial warm (cold) event called El Niño (La Niña), the term "coastal Niño (Niña)" is used. However, compared to the large basin-wide scale of El Niño/La Niña $(\sim 10000 \mathrm{~km})$ in the tropics, the coastal Niño (Niña) associated with air-sea-land interactions

\footnotetext{
* Supplemental information related to this paper is available at the Journals Online website: http://dx.doi.org/10.1175/JCLI-D-15-0112.s1.

Corresponding author address: Takeshi Doi, Japan Agency for Marine-Earth Science and Technology, 3173-25 Showa-machi, Kanazawa-ku, Yokohama 236-0001, Japan.

E-mail: takeshi.doi@jamstec.go.jp
}

occurs in the coastal sea close to the eastern edge of subtropical high and has a much smaller lateral scale of a few hundred kilometers at most. Besides the efforts to understand the mechanism of those coastal Niño/Niña events, exploring their seasonal prediction skill is equally important for various regional applications of climate information. In this regard, seasonal predictability has recently been discussed for Ningaloo Niño/Niña events along the western coast of Australia and it is found that events that co-occurred with La Niña/El Niño are predictable (Doi et al. 2013). However, no such study has been conducted for California Niño/Niña. This is the motivation of our present work.

The California Niño/Niña is associated with warm/ cold sea surface temperature (SST) anomalies off Baja California/California, which appears as the first mode of the empirical orthogonal function (EOF) explaining about $50 \%$ of interannual SST variability over the northeastern Pacific (Yuan and Yamagata 2014). Similar with the Ningaloo Niño/Niña (Kataoka et al. 2014), there are two types of the California Niño/Niña: the first type develops independently of El Niño/La Niña and matures in boreal summer, whereas the second type is closely related to El Niño/La Niña possibly through both atmospheric and oceanic teleconnections and matures in boreal winter. The influence of the El Niño/La Niña on oceanic conditions along the California coast has been 
discussed extensively in the literature (Enfield and Allen 1980; Strub and James 2002; Schwing et al. 2002; Mendelssohn et al. 2003). It is also known that there are oceanic and atmospheric bridges between the tropics and extratropics in the North Pacific (Rasmusson and Carpenter 1982; Emery and Hamilton 1985; Wallace and Gutzler 1981; Alexander et al. 2002, 2010). However, Yuan and Yamagata (2014) have demonstrated that the intrinsic coastal Bjerknes feedback is important for the evolution of the air-sea coupled mode off the west coast of California and Baja California. The coastal Bjerknes feedback may occur in the following sequence: 1) positive (negative) SST anomalies generating low (high) sea level pressure anomalies over the ocean, 2) land-sea pressure contrast induces southerly (northerly) alongshore near-surface wind anomalies, 3) acceleration of the anomalous northward (southward) ocean current and coastal downwelling (upwelling) with less (more) mixing and less (more) evaporative cooling due to reduced (increased) total winds, and 4) enhancement of the positive (negative) SST anomalies further. Both types of the California Niño/Niña last more than one season. Since the SST anomalies have potential impacts on the California Current ecosystem and regional climate including precipitation and surface temperature anomalies over the adjacent continent (Mysak 1986; Jacobson and MacCall 1995; Demer et al. 2012; Yuan and Yamagata 2014), successful prediction of such phenomena at least a few seasons ahead may contribute to a better management of social as well as industrial activities.

In this paper, we explore the seasonal prediction skill of the California Niño/Niña by use of a seasonal prediction system based on a state-of-the-art ocean-atmosphere coupled general circulation model as described in the next section. This is the first challenge and we believe that it is also useful for our further understanding of the regional climate phenomena in the midlatitudes.

\section{Numerical prediction system and observational datasets}

\section{a. Ensemble seasonal prediction by the SINTEX-F1 coupled GCM}

The seasonal prediction system adopted in this study is based on the Scale Interaction Experiment-Frontier, version 1 (SINTEX-F1) fully coupled global ocean-atmosphere circulation model (Luo et al. 2005a,b). The atmospheric model, ECHAM4.6, has a horizontal resolution of $1.125^{\circ}$ (T106) with 19 vertical levels. The oceanic model, OPA 8.2, has a horizontal resolution of about $2^{\circ} \times 2^{\circ}$ but with meridional refinement to $0.58^{\circ}$ in the tropics. It has 31 vertical levels from the surface to the bottom with a relatively finer resolution of $10 \mathrm{~m}$ from the sea surface to 110-m depth. SST, surface momentum, heat, and freshwater fluxes are exchanged every two hours without any corrections. We adopted a simple coupled SST-nudging scheme for initialization. For the hindcast period 19822013, OGCM SSTs are strongly nudged toward the NOAA OISSTv2 (Reynolds et al. 2002) in a coupled model. The AGCM forced by such generated OGCM SSTs tends to produce realistic wind stress, heat, and freshwater fluxes. The OGCM forced by the AGCM airsea fluxes in turn tends to produce realistic subsurface ocean conditions. Based on the initial conditions, we have implemented the 12-month lead prediction with the freely coupled GCM from 0000 UTC on the first day of each month of each year from 1982 to 2013, using the restart files obtained from the coupled SST-nudging run. The SINTEX-F1 prediction system has nine ensemble members with uncertainties in both initial conditions and model momentum coupling physics. More details are shown in Luo et al. (2005a). We calculate predicted anomalies by removing the model climate drifts at each lead time a posteriori using the hindcast outputs in 19832006. Also, we calculate the ensemble mean simply by averaging results from nine ensemble members. (The real-time seasonal prediction is available at http://www. jamstec.go.jp/frcgc/research/d1/iod/e/seasonal/outlook. $\mathrm{html}$.) The SINTEX-F1 prediction system is skillful in predicting not only basin-scale tropical and subtropical climate phenomena such as ENSO (Luo et al. 2005a, 2008b; Jin et al. 2008), the Indian Ocean dipole (Luo et al. 2007, 2008a), and subtropical dipole modes (Yuan et al. 2014), but also the regional climate phenomenon such as the Ningaloo Niño/Niña off the west coast of Australia (Doi et al. 2013, 2015).

\section{b. Observational datasets}

We used the NOAA OISSTv2 (Reynolds et al. 2002) for SST, the NCEP-NCAR reanalysis data (Kalnay et al. 1996) for surface wind, the Global Precipitation Climatology Project dataset (GPCP; Adler et al. 2003) for precipitation, and the Global Ocean Data Assimilation System (GODAS; Behringer et al. 1998) for sea surface height (SSH) and ocean currents in the upper $100 \mathrm{~m}$. Monthly climatologies are calculated by averaging monthly data over 1983-2006, and then anomalies are defined as deviations from the monthly mean climatologies.

\section{Results}

\section{a. California Niño index}

As a first step, we explore prediction skill for the historical time series of the California Niño index (CNI; Fig. 1), which is defined as area-averaged SST anomalies off Baja California and California $\left(20^{\circ}-30^{\circ} \mathrm{N}, 110^{\circ}-120^{\circ} \mathrm{W}\right)$ 

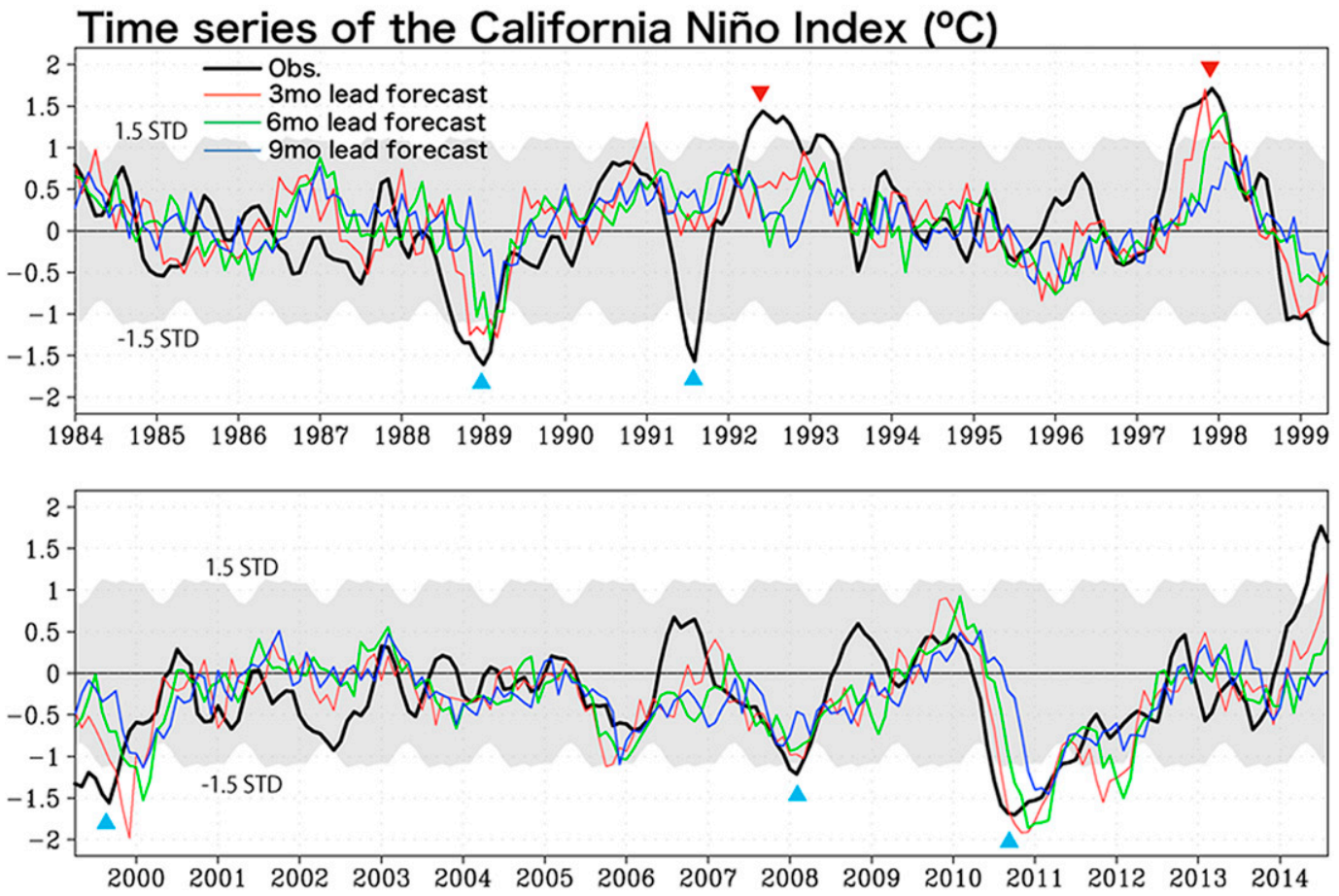

FIG. 1. The 3-month-averaged time series of the California Niño index (CNI: sea surface temperature anomalies averaged over $20^{\circ}-30^{\circ} \mathrm{N}, 110^{\circ}-120^{\circ} \mathrm{W}$, in units of ${ }^{\circ} \mathrm{C}$ ) from the observational data of NOAA OISSTv2 (black) and 3(red), 6- (green), and 9- (blue) month lead predictions along a fixed start time by the SINTEX-F1 seasonal prediction system. Gray shading denotes the range between -1.5 and 1.5 seasonal standard deviation (STD) of the observed CNI. The events with the CNI above +1.5 (below -1.5 ) STD are marked by the red (blue) triangles and selected for the case study in section $3 b$.

by Yuan and Yamagata (2014). At a glance, we see that some significant events such as the positive one in 1997/98 and negative ones in 1988/89, 1999/2000, and 2010/11 are successfully predicted several seasons in advance, though the timing of their onset stages is delayed by a few months, particularly for the 1999/2000 event. Quite intriguing is that the negative one in 1991 is not predicted at all. Before discussing each event, we show the statistical analysis for the prediction skill. Since we already know the California Niño/Nina events are somehow related to seasons, it is better to compare seasonally stratified anomaly correction coefficients (ACCs) and root-mean-square errors (RMSEs) with the persistence deterministically. Probabilistically we calculate the relative operating characteristics (ROC) scores (Mason and Graham 2002). The persistency is lower from February to April relative to the other months in a year (Fig. 2a). The seasonal prediction system is very skillful in predicting the index up to at least 6 months ahead when it is initialized on the first day of each month from January to March (Figs. 2b,c). Here we regard the prediction highly skillful when the ACC is higher than the persistence and 0.7 and the normalized RMSE is less than 1. The ROC scores also show similar features as
ACCs (Figs. 2d,e). As already mentioned, some California Niño/Niña events co-occurred with the El Niño/ La Niña with a peak in boreal winter. When we excluded the strong El Niño/La Niña years from 1984 to 2013, the prediction skill reduced for both cases, and significantly reduced for California Niña (Figs. 2d,e and 3a,c). The reduction is large for the prediction initialized on the first day of each month from October to December. When the strong El Niño/La Niña occurred, the prediction skill for the California Niño/Niña is very high (Figs. 3b and 3d). Those suggest that the high prediction skill of the El Niño (La Niña) contributes to that of the California Niño (Niña). This result also suggests that the driving mechanism of the California Niño (Niña) is related to the occurrence of the El Niño (La Niña), although some events are without co-occurrence with El Niño (La Niña) and not predicted well. As mentioned above, the SINTEX-F1 CGCM is highly skillful in predicting ENSO (Luo et al. 2005b, 2008b; Jin et al. 2008). As shown in Fig. 4, all ENSO events are successfully predicted (Fig. 4a), and the ACC skill score is beyond 0.8 and the persistence is up to a 9-month lead when the model is initialized on the first day of each month from January to March (Figs. 4b,c) despite the so-called 
Sesonally stratified ACC, RMSE, ROCS for the California Niño Index
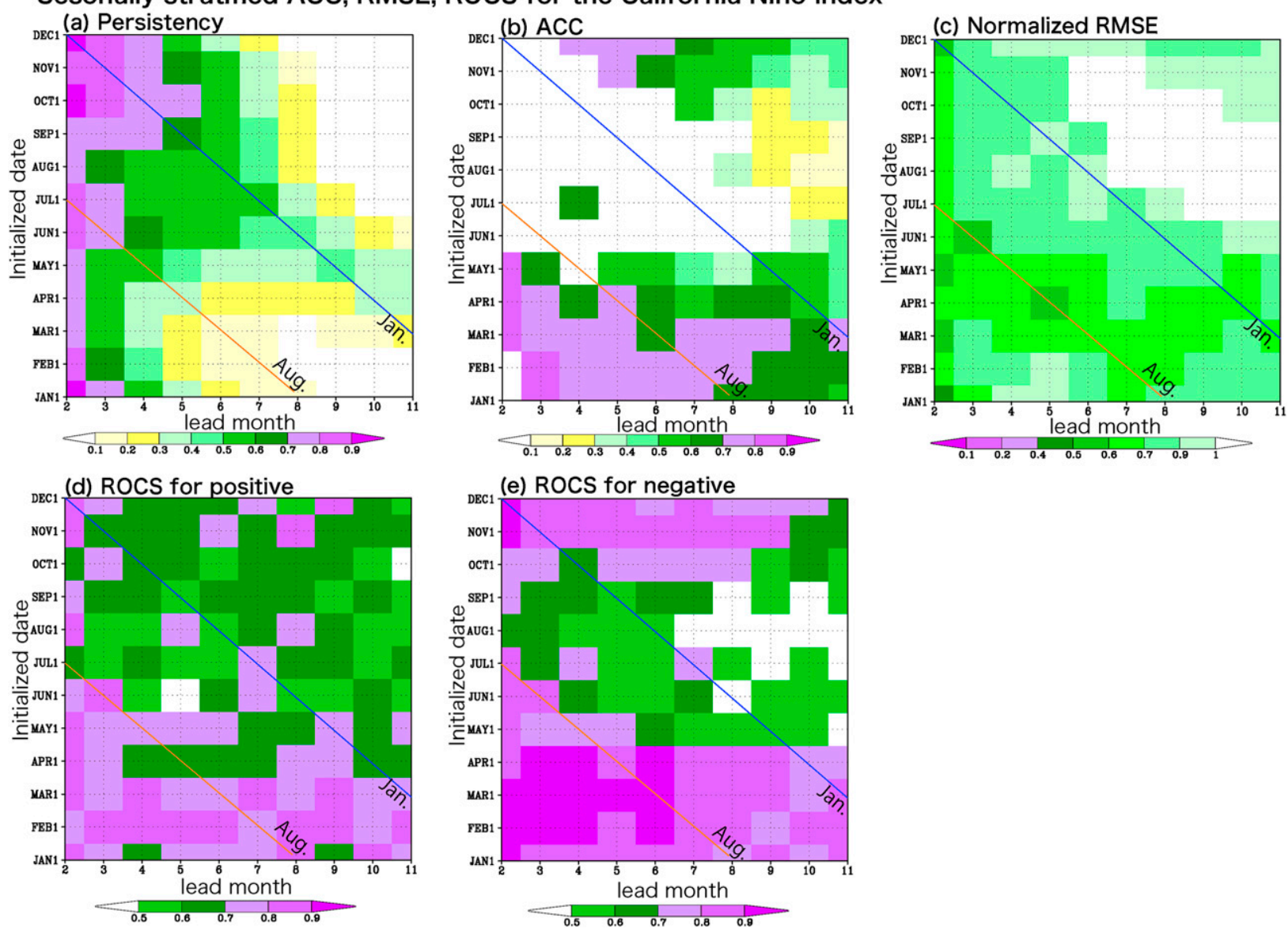

FIG. 2. (a) Seasonally stratified persistency (lag autocorrelation) for the 3-month-averaged CNI along a fixed start time in 1984-2013 from the observations. (b) Seasonally stratified ACCs for SINTEX-F1 ensemble mean prediction. The values less than the persistence are masked out. (c) Seasonally stratified RMSEs for SINTEX-F1 ensemble mean prediction normalized by the seasonal standard deviation of the observed CNI in 1984-2013. (d) Seasonally stratified leave-one-out cross-validated ROCS for the probabilistic forecasts of warmer-than-normal CNI from the SINTEX-F1 nine ensemble predictions. The threshold value for the warmer-than-normal (colderthan-normal) tercile is the coldest (warmest) value in the warmest (coldest) $33 \%$ of the observations or predictions. (e) As in (d), but for the colder-than-normal CNI.

spring barrier of ENSO prediction (cf. Goddard et al. 2001). Owing to the good prediction skill of ENSO by the SINTEX-F1 CGCM, the California Niño/Niña prediction skill is high even when the model is initialized on the first day of each month from January to March.

For more detailed analysis, California Niño (Niña) events in 1992 and 1997/98 (1989/90, 1991, 1998/99, 2007/08, and 2010/11) with the CNI above +1.5 (below -1.5 ) standard deviation are selected (Fig. 1).

\section{b. Case study}

\section{1) $1997 / 98$ CALIFORNIA NiÑO}

The 1997/98 California Niño appeared in May 1997, developed through December 1997, and matured in January 1998 (Fig. 5a). It co-occurred with the strongest
El Niño in the last 30 years (Wolter and Timlin 1998; McPhaden 1999). The prediction initialized on 1 May 1997 cannot capture the occurrence of the 1997/98 California Niño (figure not shown). However, the prediction on 1 June 1997 (Fig. 5a) captures the persistence. At this stage, the onset of this event is more difficult than to predict the persistence. Here, we focus on the prediction initialized on 1 May 1997 after the onset of event. Since the warm SST anomalies developed in May 1997 are sustained through January 1998, the information obtained even in June could be still useful for social application.

In September-November 1997, the warm SST anomaly beyond $2.5^{\circ} \mathrm{C}$ was observed off Baja California, which was associated with the high $\mathrm{SSH}$ and northward alongshore ocean current anomalies (Figs. 6a,i). The signals can be traced back to the eastern equatorial 

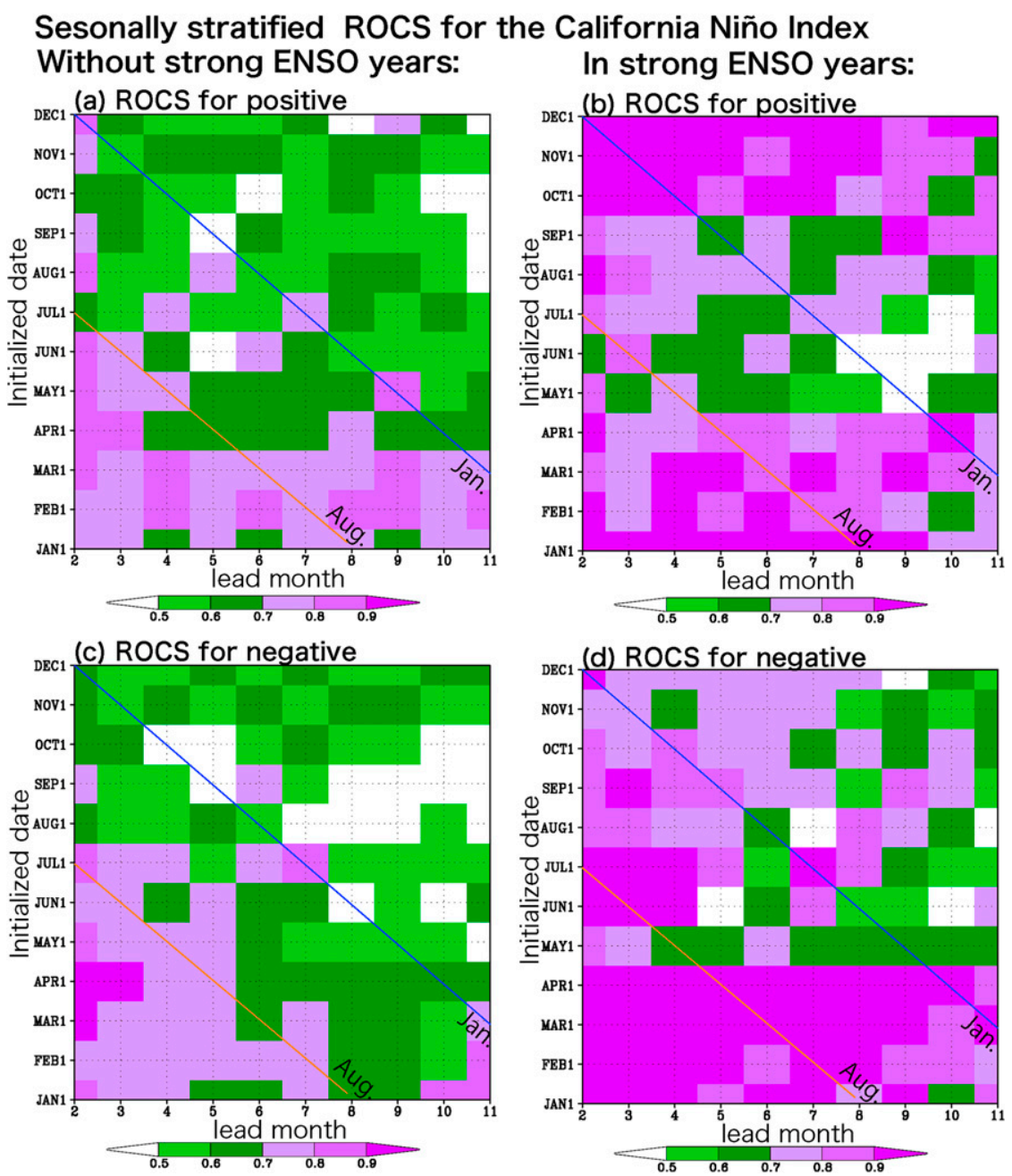

FIG. 3. (a) As in Fig. 2d, but without strong El Niño years (1987/88 and 1997/98) and La Niña years $(1988 / 89,1999 / 2000$, and 2010/11) when 3-month-averaged SST anomalies in the Niño-3.4 region $\left(5^{\circ} \mathrm{N}-5^{\circ} \mathrm{S}, 120^{\circ}-170^{\circ} \mathrm{W}\right)$ exceeded $+/-1.5^{\circ} \mathrm{C}$ for at least 3 -month periods. The threshold value for the warmer-than-normal tercile is the coldest value in the warmest $33 \%$ of the observations or predictions. (b) As in (a), but for the strong El Niño/La Niña years. (c),(d) As in (a),(b), but for the colder-than-normal tercile.

Pacific; the downwelling Kelvin waves associated with El Niño propagated eastward along the equator, reached the continental boundary, and then propagated poleward along the coast to the California Niño region. This feature was amplified in December 1997/February 1998 with the El Niño development (Figs. 6c,k). Our seasonal prediction system is skillful in predicting the 1997/98 California Niño when the model is initialized on 1 June 1997; the predicted anomalies in SST, SSH, ocean current, surface wind, and precipitation are similar to the observations except for their magnitudes (Fig. 6). Particularly, the wetter-thannormal condition over California in December 1997/ February 1998 was predicted well from the 1 June initialization (Figs. 6g,h). This successful prediction of the 1997/98 California Niño is due to the high prediction skill of the ENSO by the SINTEX-F1 prediction system (Fig. 4; Luo et al. 2005a, 2008b; Jin et al. 2008). We note that the warm event is not associated with the local southerly alongshore near-surface wind anomalies off Baja California (Figs. 6a,c), which suggests that the coastal Bjerknes feedback is not a major driver in the peak phase of the event. However, we can find the local southerly alongshore off Baja California in the onset phase of the April-May and the developing phase of the June-August 1997 (figure not shown), which may suggest the driving by the coastal Bjerknes feedback. That may contribute to the reason why the prediction of the onset of the 1997/98 warm event is more difficult than its persistence prediction. The California Niño events may have multiple drivers, the dominance of which and its 
(a) Time series of Nino 3.4 Index $\left({ }^{\circ} \mathrm{C}\right)$
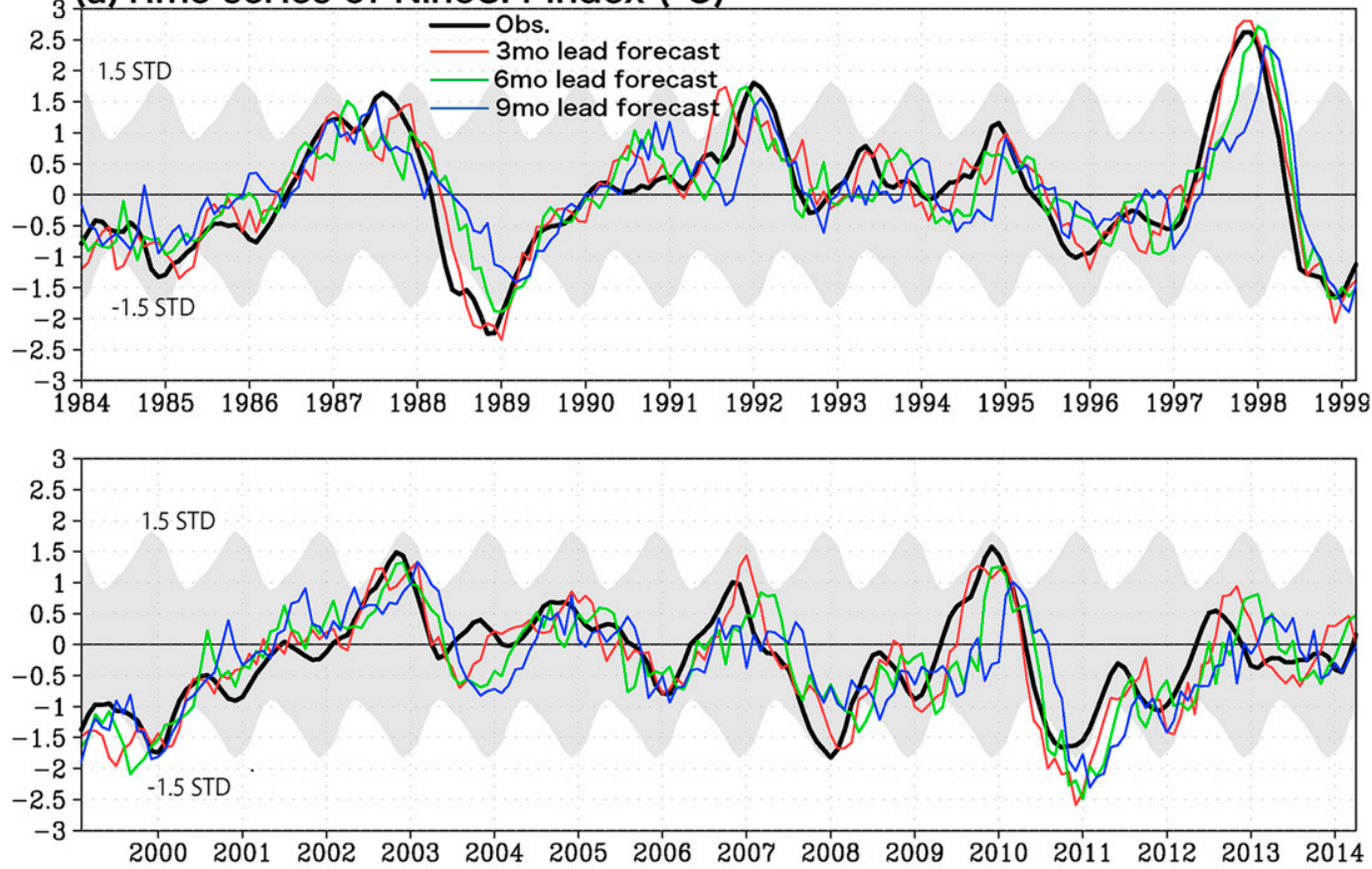

(b) Persistency

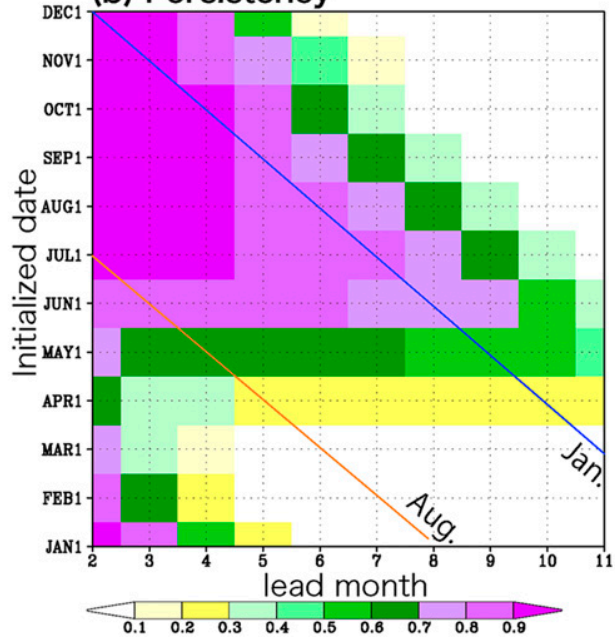

(c) ACC

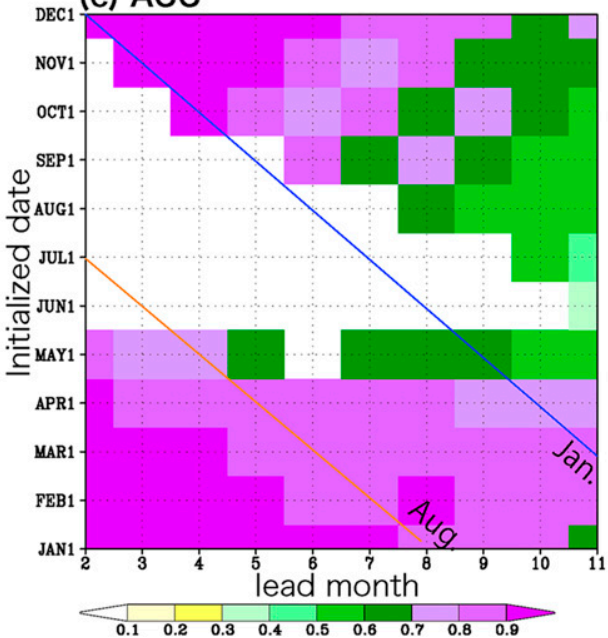

FIG. 4. (a) As in Fig. 1, but for Niño-3.4 (SST anomalies averaged over $5^{\circ} \mathrm{N}-5^{\circ} \mathrm{S}, 170^{\circ}-120^{\circ} \mathrm{W}$, in units of ${ }^{\circ} \mathrm{C}$ ). (b) As in Fig. 2a, but for Niño-3.4. (c) As in Fig. 2b, but for Niño-3.4.

predictability may change as the event evolves (e.g., Schwing et al. 2002).

\section{2) 2010/11 CALIFORNIA NiÑA AND OTHER SIMILAR EVENTS}

The 2010/11 California Niña is basically a mirror image of the 1997/98 California Niño. This was one of the long-lasting California Niña events; it occurred in May 2010, matured in October, and then persisted until April 2011 (Fig. 5b). The prediction initialized on 1 May 2010 seems to have captured the occurrence of the event in the ensemble mean (figure not shown). However, uncertainty of its evolution remains high because of the large spread in the prediction plumes. Therefore, we have shown the prediction initialized on 1 June 2010 in Fig. 5b. As shown in Figs. 5b and 7, the cold SST anomalies that developed after June 2010 and sustained through April 2011 are well predicted.

In Figs. 7i,k, the low SSH anomalies were observed off the west coast of Mexico and those may be associated with the strong 2010 La Niña via coastal upwelling Kelvin waves (Figs. 7i,k). This regional cold event is 
(a) $1997 / 98$

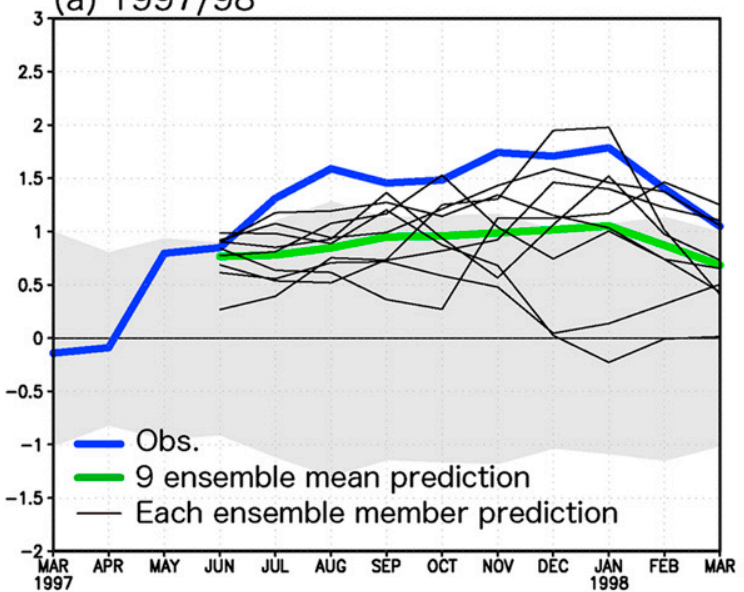

(c) 1992

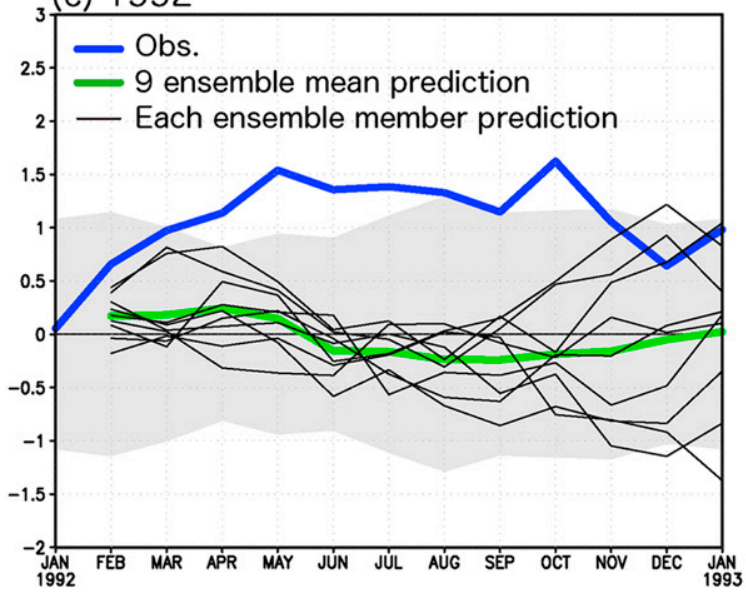

(b) 2010/11

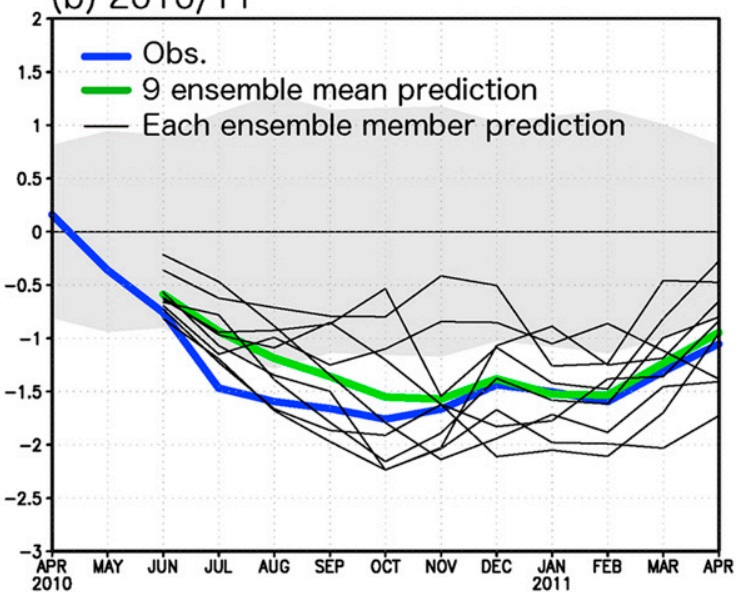

(d) 1991

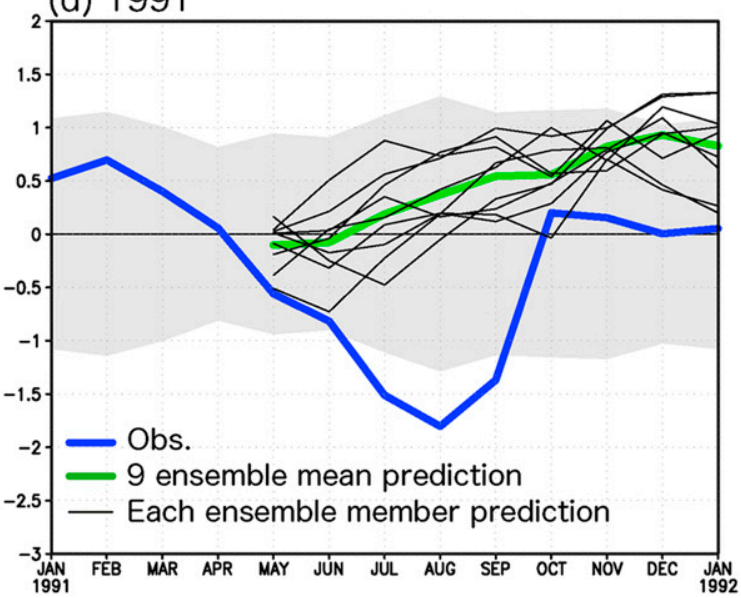

FIG. 5. (a) Monthly time series of the CNI for observational data of NOAA OISSTv2 (blue) and the SINTEX-F1 ensemble member prediction initialized on 1 Jun $1997\left({ }^{\circ} \mathrm{C}\right.$, green: 9-ensemble member mean, thin black: each member). Gray shading denotes 1.5 standard deviation of the observed CNI. (b)-(d) As in (a), but for the predictions initialized on 1 Jun 2010, 1 Feb 1992, and 1 May 1991, respectively.

successfully predicted by the 1 June 2010 initialization (Figs. $5 \mathrm{~b}$ and $7 \mathrm{~d}$ ); this may be due to high prediction skill of the 2010/11 La Niña by the SINTEX-F1 system (Fig. 4a; Doi et al. 2013). The cold event was associated with the northerly alongshore near-surface wind anomalies off Baja California, suggesting that the coastal Bjerknes feedback was also partly responsible for development of the 2010/11 California Niña (Figs. 7a,c).

The analysis and the prediction for the 1988/89,1998/99, and 2007/08 California Niña events are quite similar to that of the 2010/11 California Niña (see Fig. 8 and Supplementary Figs. 1-3). Those are predicted reasonably well about two seasons ahead because of their as sociation with La Niña, except that the model underestimated the events. We expect that the coarse zonal resolution of about $2^{\circ}$ in the present ocean component may be insufficient in resolving coastal Kelvin wave dynamics. Another reason may be the deficiency in resolving the coastal Bjerknes feedback including the land-sea pressure contrast. In this context, we note that the model prediction skill of the 1998/99 California Niña is not as high because only weak La Niña co-occurred in the tropics and the coastal Bjerknes feedback may have played a more important role on its development (Supplementary Fig. 2).

\section{3) 1992 CALIFORNIA NIÑO}

The 1992 California Niño appeared in February and developed through May 1992 (Fig. 5c). It persisted through October 1992, and then suddenly decayed. This warm event could not be predicted by the SINTEX-F1 system initialized on 1 February 1992 (Figs. 1, 5c, and 9). During the developing phase in February-April 1992, the warm SST, the local southerly alongshore wind at surface, the local northward alongshore current, and the high SSH anomalies were observed off Baja California (Fig. 9). 
Obs. v.s. Predicted from 1 jun1997 ini. Pre-season: SON1997
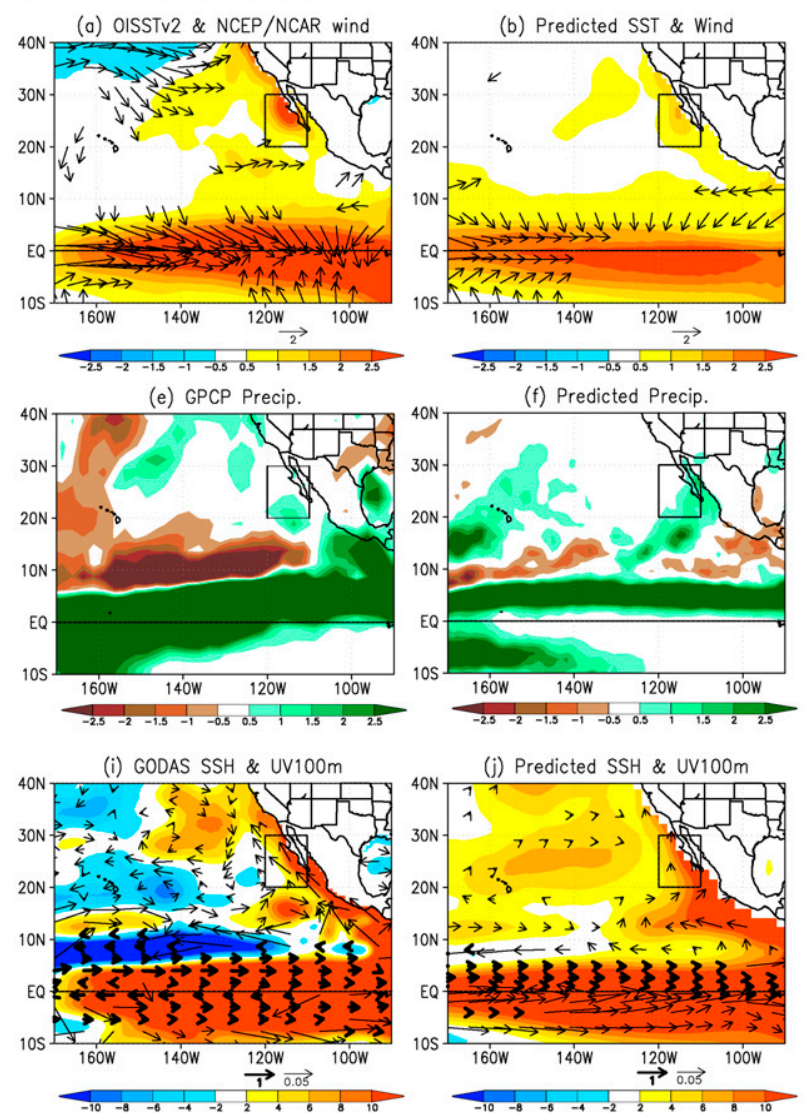
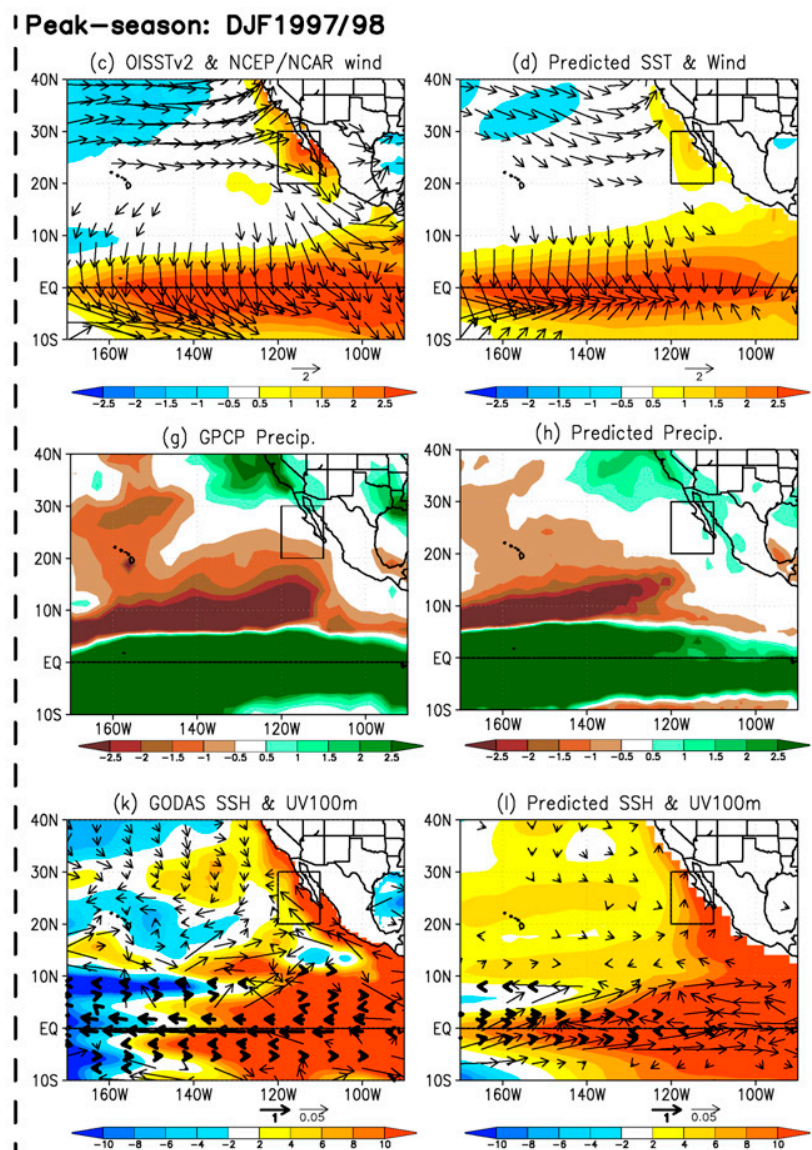

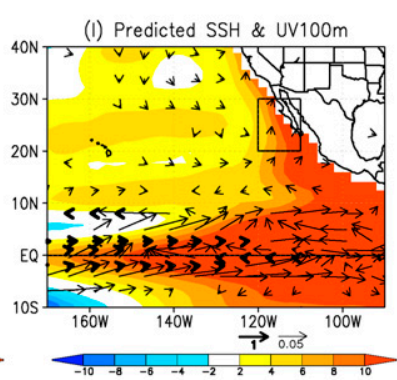

FIG. 6. (a) SST anomalies $\left({ }^{\circ} \mathrm{C}\right.$, shaded) and 10-m surface wind speed anomalies ( $\mathrm{m} \mathrm{s}^{-1}$, vector, only wind speed above $1 \mathrm{~m} \mathrm{~s}^{-1}$ is shown) from the OISST and NCEP-NCAR, (e) precipitation anomalies from GPCP, and (i) SSH anomalies (10 ${ }^{-2} \mathrm{~m}$, shaded) and ocean current

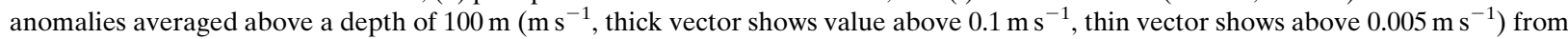
the assimilation data of GODAS for the period of September-November 1997. The region for the California Niño index is enclosed by the black box. (b),(f),(j) As in (a),(e),(i), but for the ensemble mean predictions initialized on 1 Jun 1997. (c),(g),(k) As in (a),(e),(i), but for the period of December 1997/February 1998. (d),(h),(l) As in (b),(f),(j), but for the period of December 1997/February 1998.

This suggests that the coastal Bjerknes feedback mechanism is a major driver for the development of this warm event in contrast to the $1997 / 98$ event, even if it is partly influenced by the 1991/92 El Niño. Since the development of the 1992 California Niño is not dominated only by El Niño, our seasonal prediction system initialized on 1 February 1992 underestimates the warm event (Fig. 9b).

\section{4) 1991 CALIFORNIA NiÑA}

The 1991 California Niña is basically a mirror image of the 1992 California Niño. It appeared in May, matured in August, and then rapidly decayed in October (Fig. 5d). In the developing phase in May-June 1991, the cold SST, the local northerly alongshore wind at surface, and the low SSH anomalies were observed off Baja California (Fig. 10). This suggests that the coastal Bjerknes feedback operated effectively to generate the cold event. We note that the equatorial Pacific was almost in a neutral state (Fig. 10a). This suggests that this cold event was locally developed and not closely related to ENSO. As expected, this locally amplified cold event is not predicted by the present seasonal prediction system initialized on 1 May 1991.

\section{Discussion}

The potential source of seasonal predictability in the midlatitude Pacific is mostly related to the teleconnection from the ocean-atmosphere coupled phenomenon ENSO in the tropics (e.g., Bjerknes 1969). Yuan and Yamagata (2014) have recently catalogued the California Niño/Niña as a regional coupled climate phenomenon. Since the new climate mode influences the regional marine and terrestrial climate around California, the prediction of possible 
Obs. v.s. Predicted from 1 jun2010 ini. Pre-season: JJA2010
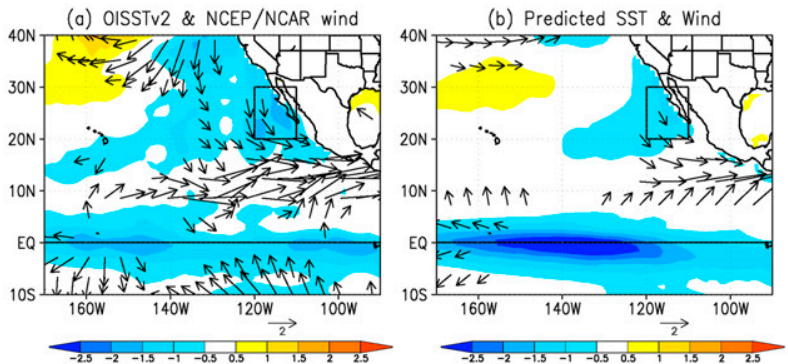

(e) GPCP Precip.

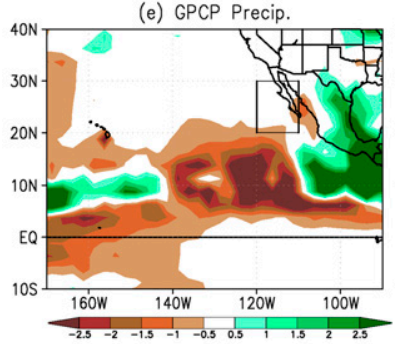

(i) GODAS SSH \& UV $100 \mathrm{~m}$

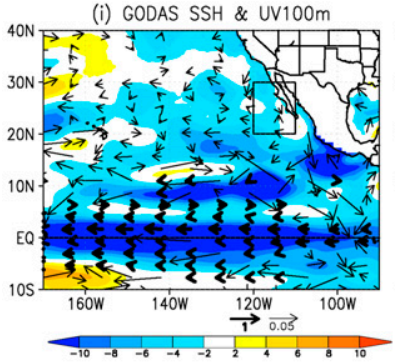

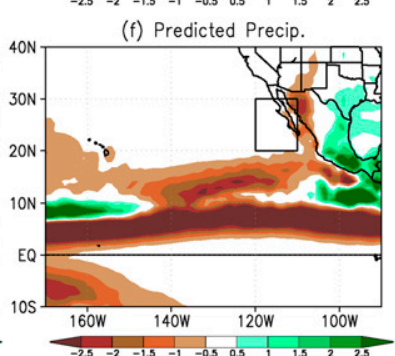

(j) Predicted SSH \& UV100m

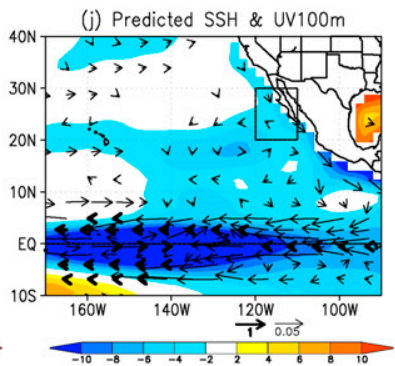

I Peak-season: SON2010
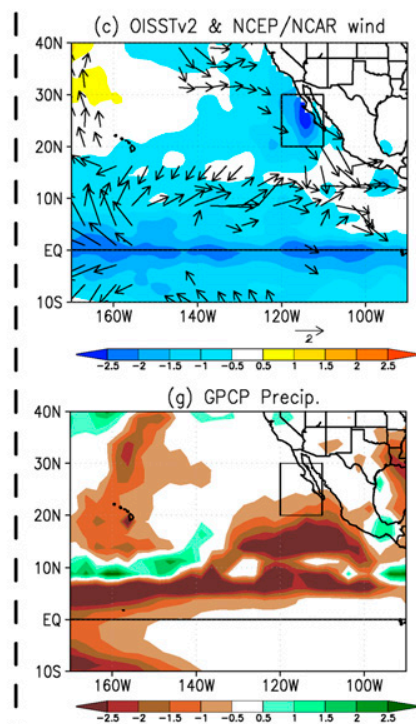

(k) GODAS SSH \& UV $100 \mathrm{~m}$

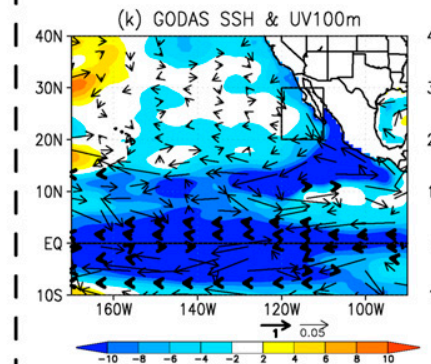

(d) Predicted SST \& Wind

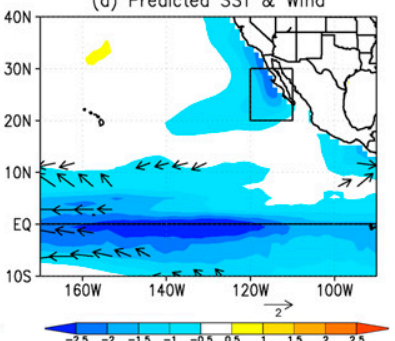

(h) Predicted Precip

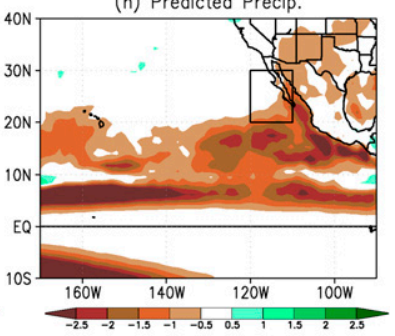

(I) Predicted SSH \& UV $100 \mathrm{~m}$

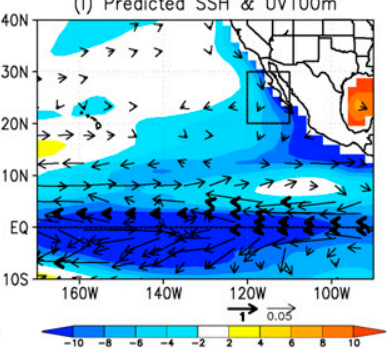

FIG. 7. As in Fig. 6, but for the period of (left) June-August 2010 and (right) September-November 2010. The SINTEX-F1 seasonal prediction was initialized on 1 Jun 2010.

events may open a new door to the regional midlatitude seasonal prediction. This situation is very similar to the Ningaloo Niño off Western Australia facing the Indian Ocean (Doi et al. 2013, 2015). The present work is the first step in such a research stream for the California Niño/ Niña and, using the SINTEX-F1 seasonal prediction system, we have explored the seasonal prediction skill of the
California Niño (Niña). We have found that the California Niño (Niña) co-occurring with El Niño (La Niña) is predictable at least two seasons ahead. However, locally amplified, intrinsic California Niño (Niña), which is independent of El Niño (La Niña) is not predictable (or highly underestimated) by the present seasonal prediction system.
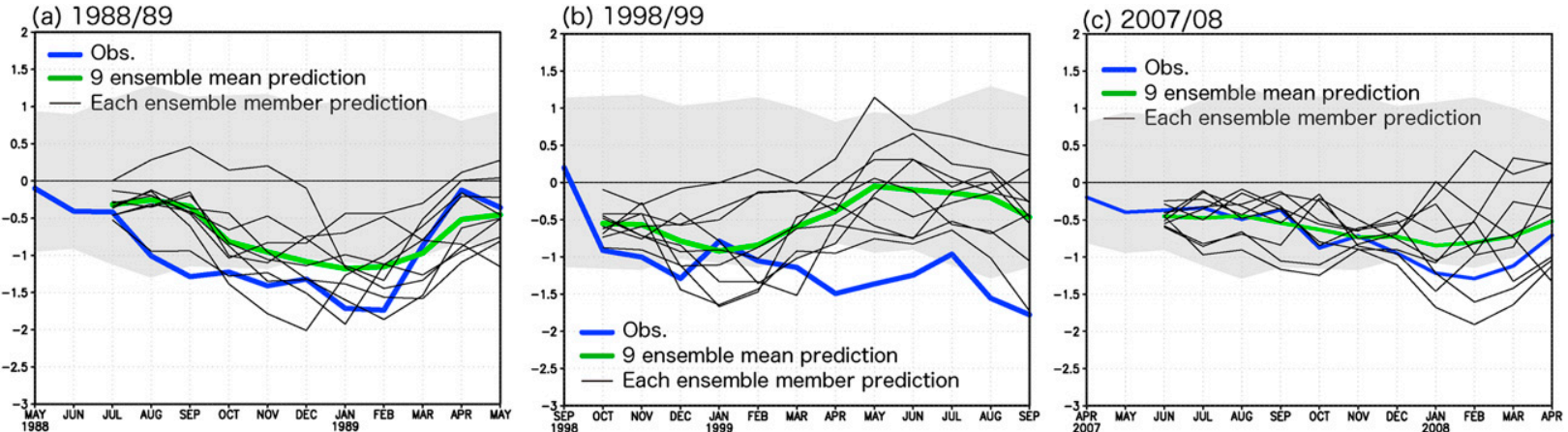

FIG. 8. As in Fig. 5, but for the initializations on (a) 1 Jul 1998, (b) 1 Oct 1998, and (c) 1 Jun 2007. 


\section{Obs. v.s. Predicted from 1 feb1992 ini. Pre-season: FMA1992}
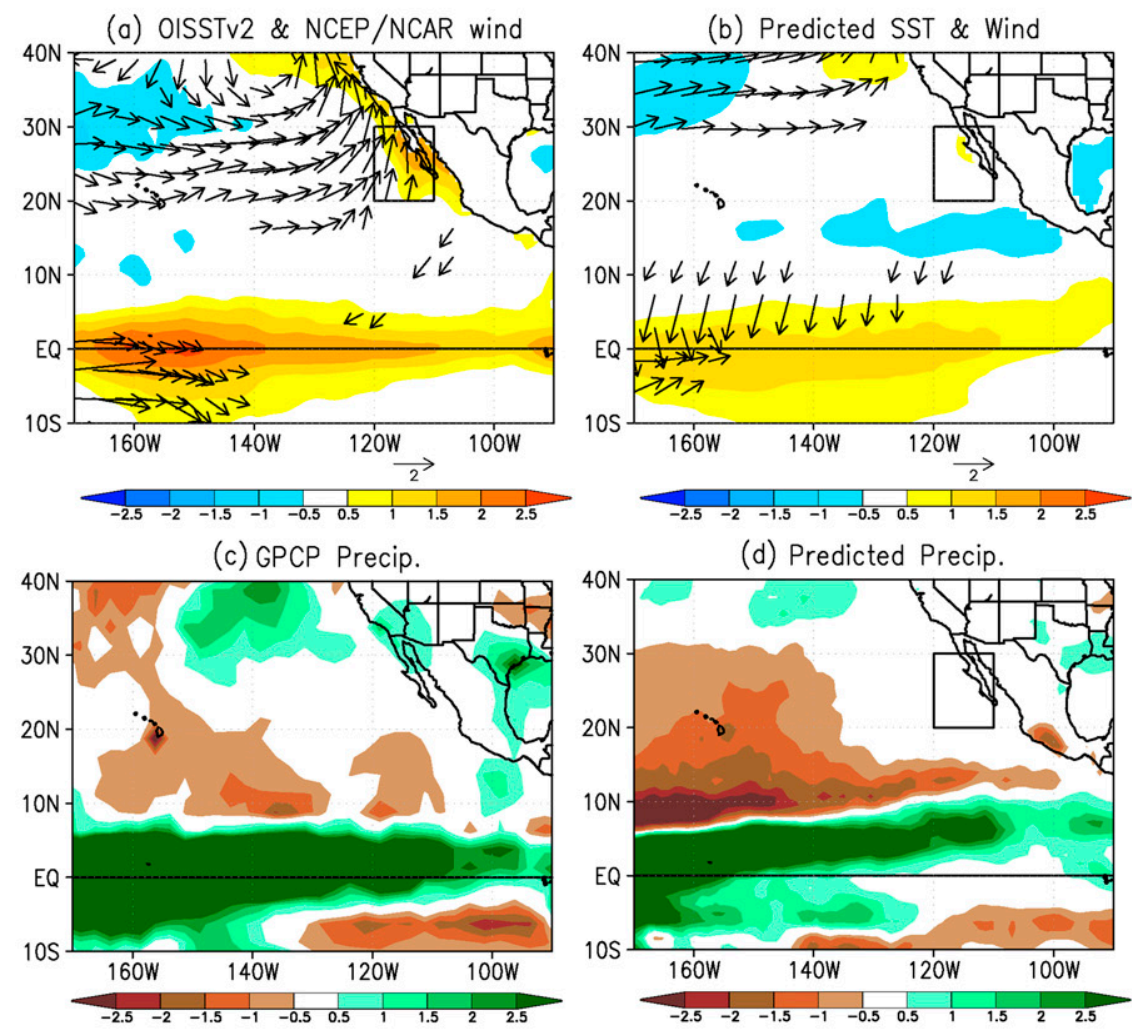

(e) GODAS SSH \& UV $100 \mathrm{~m}$
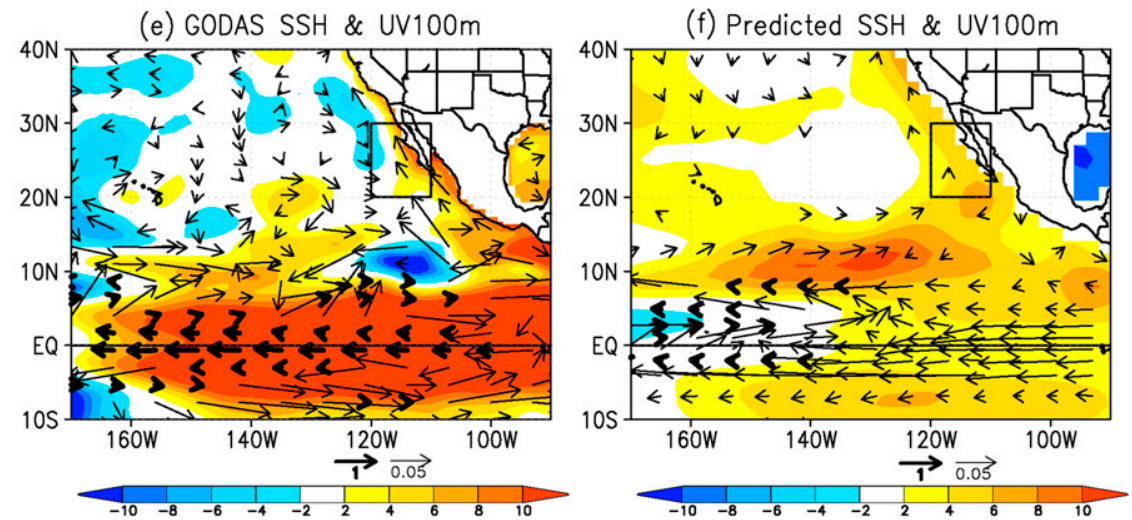

FIG. 9. As in Fig. 6, but for the period of Feb-April 1992. The SINTEX-F1 seasonal prediction was initialized on 1 Feb 1992.

The California Niño/Niña may have large impacts on the regional fishery and ecosystems (Reimer et al. 2015; Demer et al. 2012; Jacobson and MacCall 1995; Mysak 1986). Also, it may influence the regional agriculture including wineries. We note that California faced the worst drought on record in the boreal winter of 2013/14 (Griffin and Anchukaitis 2014; Wang et al. 2014). It might have been due not only to the La Niña-like condition in the eastern tropical Pacific, but also to the
California Niña at that time. We believe that early prediction of such a regional climate mode may open a door to industrial as well as social applications.

A key to improve the prediction skill lies in the ability of the model to capture the combination of local and remote forcing in the California Niño region. Particularly, further analysis is necessary for coastal Kelvin waves and their predictability using higher temporal and spatial resolution observations and models. The model 


\section{Obs. v.s. Predicted from 1 may 1991 ini. Pre-season: MJ1991}

(a) OISSTv2 \& NCEP/NCAR wind

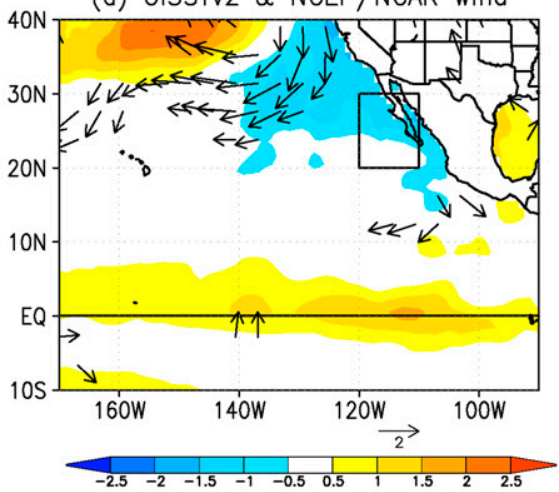

(c) GPCP Precip.

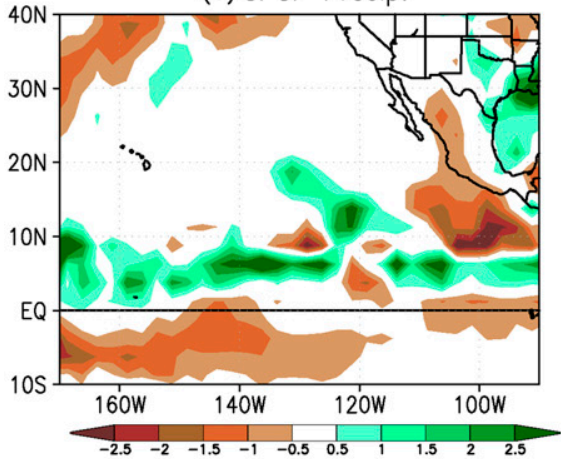

(e) GODAS SSH \& UV100m

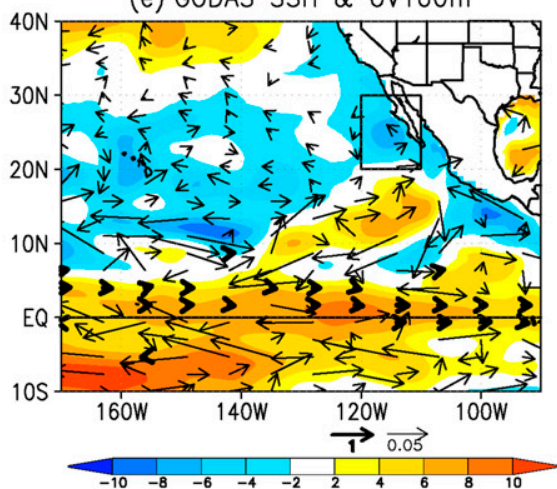

(b) Predicted SST \& Wind

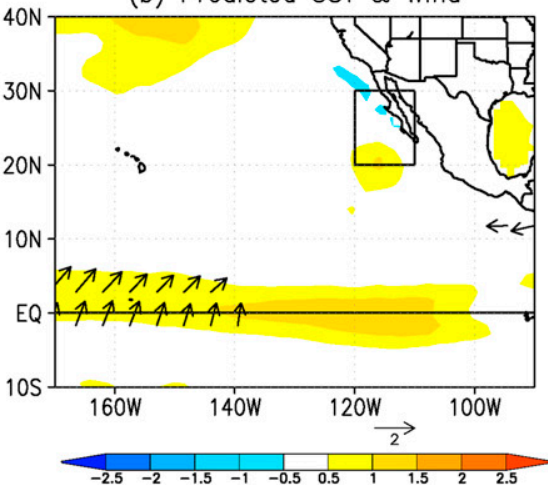

(d) Predicted Precip.

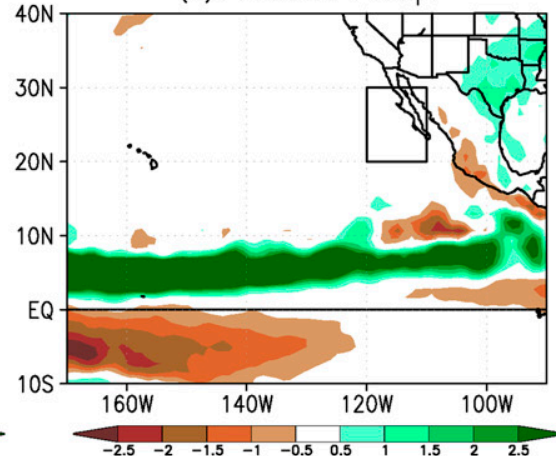

(f) Predicted SSH \& UV100m

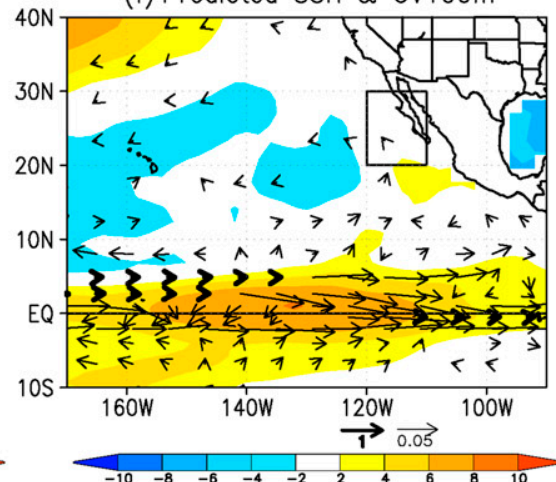

FIG. 10. As in Fig. 6, but for the period of May-July 1991. The SINTEX-F1 seasonal prediction was initialized on 1 May 1991.

underestimates coastal Kelvin waves from the equatorial region, which may be responsible for the generation of the California Niño/Niña. It may be improved by increasing the horizontal resolution of the ocean component of the coupled model. Another key is the coastal Bjerknes feedback with air-sea-land processes. The feedback cannot be captured well by the present coarse spatial resolution of the model (atmosphere: $1.125^{\circ}$, ocean: about $\left.2^{\circ} \times 2^{\circ}\right)$. Also, the simple coupled SST-nudging initialization for the present seasonal prediction system may have limitations in the prediction skill of the regional climate phenomena. This is because the mixedlayer depth anomaly is expected to play an important role in determining the SST evolution, particularly in the subtropical climate phenomenon (Doi et al. 2010; Morioka et al. 2010). Dense observational data off Baja California and California, and a new initialization scheme with a suitable three-dimensional variational data assimilation 
(3DVAR) method may improve the prediction skill of California Niño/Niña. We are developing a new higherresolution version of the seasonal prediction system called SINTEX-F2 with such a new initialization scheme. Also, we are now preparing its dynamical downscaling for the California Niño region by a high-resolution regional coupled model to capture the interaction of a combination of local and remote forcing there and its change as the event evolves as the next step.

Acknowledgments. The SINTEX-F1 seasonal climate prediction system was produced by the Earth Simulator at JAMSTEC. We are grateful to Drs. Jing-Jia Luo, Sebastian Masson, and our European colleagues of INGV/CMCC and Laboratoire d'Océanographie et du Climat: Expérimentations et Approches Numériques (L'OCEAN) for their contribution to developing the prototype of the system. This research was supported by the Environment Research and Technology Development Fund (2-1405) of the Ministry of the Environment, Japan.

\section{REFERENCES}

Adler, R. F., and Coauthors, 2003: The version-2 Global Precipitation Climatology Project (GPCP) monthly precipitation analysis (1979-present). J. Hydrometeor., 4, 1147-1167, doi:10.1175/ 1525-7541(2003)004<1147:TVGPCP $>2.0$. CO;2.

Alexander, M. A., I. Blade, M. Newman, J. R. Lanzante, N.-C. Lau, and J. D. Scott, 2002: The atmospheric bridge: The influence of ENSO teleconnections on air-sea interaction over the global oceans. J. Climate, 15, 2205-2231, doi:10.1175/1520-0442(2002)015<2205: TABTIO $>2.0 . \mathrm{CO} ; 2$.

—, D. J. Vimont, P. Chang, and J. D. Scott, 2010: The impact of extratropical atmospheric variability on ENSO: Testing the seasonal footprinting mechanism using coupled model experiments. J. Climate, 23, 2885-2901, doi:10.1175/ 2010JCLI3205.1.

Behringer, D. W., M. Ji, and A. Leetmaa, 1998: An improved coupled model for ENSO prediction and implications for ocean initialization. Part I: The ocean data assimilation system. Mon. Wea. Rev., 126, 1013-1021, doi:10.1175/1520-0493(1998)126<1013: AICMFE $>2.0 . \mathrm{CO} ; 2$.

Bjerknes, J., 1969: Atmospheric teleconnections from the equatorial Pacific. Mon. Wea. Rev., 97, 163-172, doi:10.1175/ 1520-0493(1969)097<0163:ATFTEP > 2.3.CO;2.

Demer, D. A., J. P. Zwolinski, K. A. Byers, G. R. Cutter, J. S. Renfree, T. S. Sessions, and B. J. Macewicz, 2012: Prediction and confirmation of seasonal migration of Pacific sardine (Sardinops segax) in the California Current Ecosystem. Fish Bull., 100, 52-70.

Depczynski, M., and Coauthors, 2013: Bleaching, coral mortality and subsequent survivorship on a West Australian fringing reef. Coral Reefs, 32, 233-288, doi:10.1007/ s00338-012-0974-0.

Doi, T., T. Tozuka, and T. Yamagata, 2010: The Atlantic meridional mode and its coupled variability with the Guinea Dome. J. Climate, 23, 455-475, doi:10.1175/2009JCLI3198.1.

— S. K. Behera, and T. Yamagata, 2013: Predictability of the Ningaloo Niño/Niña. Sci. Rep., 3, doi:10.1038/srep02892.
,-- , and $-, 2015:$ An interdecadal regime shift in rainfall predictability related to the Ningaloo Niño in the late 1990s. J. Geophys. Res. Oceans, 120,1388-1396, doi:10.1002/2014JC010562.

Emery, W., and D. Hamilton, 1985: Atmospheric forcing of interannual variability in the northeast Pacific Ocean: Connections with El Niño. J. Geophys. Res., 90, 857-868, doi:10.1029/ JC090iC01p00857.

Enfield, D. B., and J. S. Allen, 1980: On the structure and dynamics of monthly mean sea level anomalies along the Pacific coast of North and South America. J. Phys. Oceanogr., 10, 557-578, doi:10.1175/1520-0485(1980)010<0557:OTSADO>2.0.CO;2.

Feng, M., M. J. McPhaden, S.-P. Xie, and J. Hafner, 2013: La Niña forces unprecedented Leeuwin Current warming in 2011. Sci. Rep., 3, 1277, doi:10.1038/srep01277.

Goddard, L., S. J. Mason, S. E. Zebiak, C. F. Ropelewski, R. Basher, and M. A. Cane, 2001: Current approaches to seasonal to interannual climate predictions. Int. J. Climatol., 21, 11111152, doi:10.1002/joc.636.

Griffin, D., and K. J. Anchukaitis, 2014: How unusual is the 2012 2014 California drought? Geophys. Res. Lett., 41, 9017-9023, doi:10.1002/2014GL062433.

Jacobson, L. D., and A. D. MacCall, 1995: Stock-recruitment models for Pacific sardine (Sardinops segax). Can. J. Fish. Aquat. Sci., 52, 566-577, doi:10.1139/f95-057.

Jin, E. K., and Coauthors, 2008: Current status of ENSO prediction skill in coupled ocean-atmosphere models. Climate Dyn., 31, 647-664, doi:10.1007/s00382-008-0397-3.

Kalnay, E., and Coauthors, 1996: The NCEP/NCAR 40-Year Reanalysis Project. Bull. Amer. Meteor. Soc., 77, 437-471, doi:10.1175/ 1520-0477(1996)077<0437:TNYRP>2.0.CO;2.

Kataoka, T., T. Tozuka, S. K. Behera, and T. Yamagata, 2014: On the Ningaloo Niño/Niña. Climate Dyn., 43, 1463-1482, doi:10.1007/ s00382-013-1961-z.

Luo, J.-J., S. Masson, S. Behera, S. Shingu, and T. Yamagata, 2005a: Seasonal climate predictability in a coupled OAGCM using a different approach for ensemble forecasts. J. Climate, 18, 4474-4494, doi:10.1175/JCLI3526.1.

_ — - E. Roeckner, G. Madec, and T. Yamagata, 2005b: Reducing climatology bias in an ocean-atmosphere OGCM with improved coupling physics. J. Climate, 18, 2344-2360, doi:10.1175/JCLI3404.1.

,-- S. Behera, and T. Yamagata, 2007: Experimental forecasts of Indian Ocean dipole using a coupled OAGCM. J. Climate, 20, 2178-2190, doi:10.1175/JCLI4132.1.

_- S. Behera, Y. Masumoto, H. Sakuma, and T. Yamagata, 2008a: Successful prediction of the consecutive IOD in 2006 and 2007. Geophys. Res. Lett., 35, 1-6, doi:10.1029/2007GL032793.

_ S. Masson, S. Behera, and T. Yamagata, 2008b: Extended ENSO predictions using a fully coupled ocean-atmosphere model. J. Climate, 21, 84-93, doi:10.1175/2007JCLI1412.1.

Mason, S. J., and N. E. Graham, 2002: Areas beneath the relative operating characteristics (ROC) and relative operating levels (ROL) curves: Statistical significance and interpretation. Quart. J. Roy. Meteor. Soc., 128, 2145-2166, doi:10.1256/ 003590002320603584.

McPhaden, M. J., 1999: Genesis and evolution of the 1997-98 El Nino. Science, 283, 950-954, doi:10.1126/science.283.5404.950.

Mendelssohn, R., F. B. Schwing, and S. J. Bograd, 2003: Spatial structure of subsurface temperature variability in the California Current, 1950-1993. J. Geophys. Res., 108, 3093, doi:10.1029/ 2002JC001568.

Morioka, Y., T. Tozuka, and T. Yamagata, 2010: Climate variability in the southern Indian Ocean as revealed by self-organizing 
maps. Climate Dyn., 35, 1059-1072, doi:10.1007/ s00382-010-0843-x.

Mysak, L., 1986: El Niño, interannual variability and fisheries in the northeast Pacific Ocean. Can. J. Fish. Aquat. Sci., 43, 464-497, doi:10.1139/f86-057.

Pearce, A. F., and M. Feng, 2013: The rise and fall of the "marine heat wave" off Western Australia during the summer of 2010/11. J. Mar. Syst., 111-112, 139-156, doi:10.1016/j.jmarsys.2012.10.009.

Rasmusson, E. M., and T. H. Carpenter, 1982: Variations in tropical sea surface temperature and surface wind fields associated with the Southern Oscillation/El Niño. Mon. Wea. Rev., 110, 354-384 doi:10.1175/1520-0493(1982)110<0354:VITSST>2.0.CO;2.

Reimer, J. J., R. Vargas, D. Rivas, G. Gaxiola-Castro, J. M. Hernandez-Ayon, and R. Lara-Lara, 2015: Sea surface temperature influence on terrestrial gross primary production along the southern California Current. PLoS One, 10, e0125177, doi:10.1371/journal.pone.0125177.

Reynolds, R. W., N. A. Rayner, T. M. Smith, D. C. Stokes, and W. Wang, 2002: An improved in situ and satellite SST analysis for climate. J. Climate, 15, 1609-1625, doi:10.1175/ 1520-0442(2002)015<1609:AIISAS > 2.0.CO;2.

Richter, I., S. K. Behera, Y. Masumoto, B. Taguchi, N. Komori, and T. Yamagata, 2010: On the triggering of Benguela Niños: Remote equatorial versus local influences. Geophys. Res. Lett., 37, L20604, doi:10.1029/2010GL044461.

Schwing, F. B., T. Murphree, L. deWitt, and P. M. Green, 2002: The evolution of oceanic and atmospheric anomalies in the northeast Pacific during the El Niño and La Niña events of 1995-2001. Prog. Oceanogr., 54, 459-491, doi:10.1016/ S0079-6611(02)00064-2.

Shannon, L. V., A. J. Boyd, G. B. Brundrit, and J. Taunton-Clark, 1986: On the existence of an El Niño-type phenomenon in the
Benguela system. J. Mar. Res., 44, 495-520, doi:10.1357/ 002224086788403105.

Strub, P. T., and C. James, 2002: Altimeter-derived surface circulation in the large-scale NE Pacific gyres: Part 2. 1997-1998 El Niño anomalies. Prog. Oceanogr., 53, 185-214, doi:10.1016/ S0079-6611(02)00030-7.

Tozuka, T., T. Kataoka, and T. Yamagata, 2014: Locally and remotely forced atmospheric circulation anomalies of Ningaloo Niño/Niña. Climate Dyn., 43, 2197-2205, doi:10.1007/ s00382-013-2044-x.

Wallace, J. M., and D. S. Gutzler, 1981: Teleconnections in the geopotential height field during the Northern Hemisphere winter. Mon. Wea. Rev., 109, 784-812, doi:10.1175/ 1520-0493(1981)109<0784:TITGHF $>2.0 . \mathrm{CO} ; 2$

Wang, S.-Y., L. Hipps, R. R. Gillies, and J.-H. Yoon, 2014: Probable causes of the abnormal ridge accompanying the 2013-2014 California drought: ENSO precursor and anthropogenic warming footprint. Geophys. Res. Lett., 41, 3220-3226, doi:10.1002/ 2014 GL059748.

Wolter, K., and M. S. Timlin, 1998: Measuring the strength of ENSO events: How does 1997/98 rank? Weather, 53, 315-324, doi:10.1002/j.1477-8696.1998.tb06408.x.

Yuan, C., and T. Yamagata, 2014: California Niño/Niña. Sci. Rep., 4, 4801, doi:10.1038/srep04801.

— - T. Tozuka, J. Luo, and T. Yamagata, 2014: Predictability of the subtropical dipole modes in a coupled ocean-atmosphere model. Climate Dyn., 42, 1291-1308, doi:10.1007/s00382-013-1704-1.

Zinke, J., A. Rountrey, M. Feng, S.-P. Xie, D. Dissard, K. Rankenburg, J. M. Lough, and M. T. McCulloch, 2014: Corals record long-term Leeuwin Current variability including Ningaloo Niño/Niña since 1975. Nat. Commun., 5, 3607, doi:10.1038/ncomms4607. 